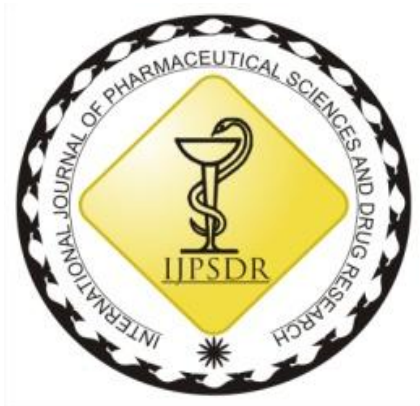

ISSN: 0975-248X

RESEARCH ARTICLE CODEN (USA): IJPSPP

$(\mathrm{cc})$ EY-NG-SA

\title{
In vitro Antimicrobial Susceptibility Testing of Bacterial Isolates Causing Wound Infection in a Tertiary Care Hospital, Port Harcourt, Nigeria
}

\author{
N. O. Ezenobi*, H. I. Ogbu, G. O. Musa \\ Department of Pharmaceutical Microbiology and Biotechnology, Faculty of Pharmaceutical Sciences, University of Port \\ Harcourt, University Park, Rivers State, Nigeria
}

Copyright (C) 2019 N. O. Ezenobi et al. This is an open access article distributed under the terms of the Creative Commons AttributionNonCommercial-ShareAlike 4.0 International License which allows others to remix, tweak, and build upon the work non-commercially, as long as the author is credited and the new creations are licensed under the identical terms.

\begin{abstract}
A successful treatment of wound infection is determined by the proper identification and evaluation of the varied types of microorganisms that colonize the wound surface. Such evaluation will include an antimicrobial susceptibility profiling of the invading pathogen(s) in order to implement an effective and pathogen specific treatment. The antimicrobial susceptibility profile of the bacterial species isolated from wound infections was tested to provide basis for their prudent use as antimicrobials. The standard method of antibiotic sensitivity testing with single antibiotic disc was employed in the analysis. The bacterial isolates tested were Staphylococcus aureus, Escherichia coli, Pseudomonas aeruginosa and Klebsiella pneumoniae. The organisms were isolated from samples collected from patients at different wards at the University of Port Harcourt Teaching Hospital, Port Harcourt, Nigeria. The number and percentage occurrence of each individual bacterium encountered varied among the isolates. Pseudomonas aeruginosa has the highest frequency of occurrence of $48.6 \%$ accounting for 36 of the 74 bacterial isolates. This was followed by Staphylococcus aureus and Escherichia coli accounting for 17 (23.0\%) and 11 (14.9\%) respectively. Klebsiella pneumoniae was the least prevalent bacteria species accounting for $10(13.5 \%)$ of the total bacterial count. The study shows imipenem as the most potent antimicrobial agent against the isolates tested. The isolates were moderately sensitive to gentamicin, ciprofloxacin and levofloxacin, but highly resistance to ceftazidime, erythromycin, sulphamethoxazole/trimethoprim, cefepime, amoxicillin/clavulanic acid and aztreonam. The study further reiterates the need for prudent use and control of antimicrobials.
\end{abstract}

Keywords: Antibiotics, susceptibility, resistance, wound infection, bacterial isolates.

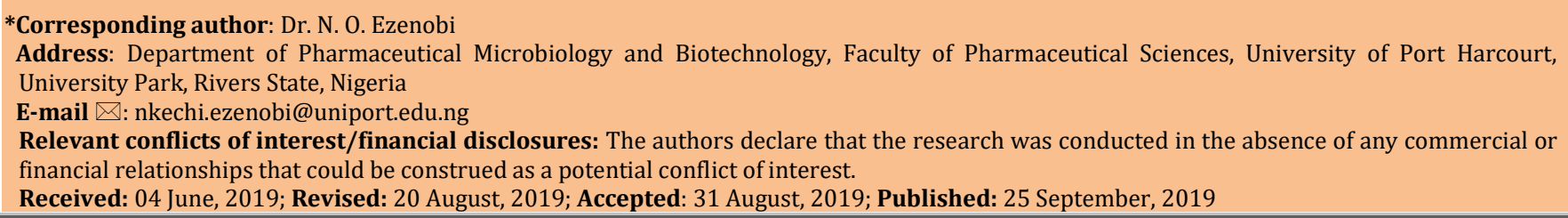

\section{INTRODUCTION}

One of the key functions of a normal or intact skin as earlier indicated is to ensure that there no proliferation of undesirable microbes (that can cause a disease) on the skin surface and the underlying tissues. ${ }^{[1-2]}$ In the event of a breakage in the continuity of the skin a 
disease condition may arise obviously due to the presence of undesirable microbes. [3-5] These invading organisms could be aerobic or anaerobic organisms varying in time and location of infections. [6] Increasingly, newer pathogens are being identified in different kinds of wound infections and these organisms as previously reported may be difficult to identify drugs. [7] In some way become resistant to most of the available antimicrobial drugs and may as well contribute to the nonhealing of wounds that do not exhibit clinical signs of infection. [3, 7] In managing wound infection, several factors would have to be considered collectively to assess the probability of infection. Earlier reports have considered factors such as type of wound, location of the wound, microbial density, microbial type. [3, 8-9] Other important factors include certain disease conditions such as cancer, diabetes, poor blood supply to the wound and host immune response. [3]

Majority of the wound's infections reported in several literatures show Staphylococcus aureus as the causative organism. [2, 7, 10-11] Pseudomonas aeruginosa seems to account for $5-15 \%$ of nosocomial infections with infection mainly following burns and surgery. [2, 10] Escherichia coli is seen as a common inhabitant of the human and animal gut, but can also be found in water, soil, vegetation, wounds, otitis media and other complications in humans. ${ }^{[7,12]}$ Earlier report affirms the occurrence of an infection when virulence factor(s) is expressed by one or more microorganisms in a wound to the extent that it out compete the host natural immune system and subsequently invades and disseminates microorganisms in viable tissue and so provokes a series of local and systemic host responses. [3] The responses may give rise to cellulitis around the wound following a purulent discharge or painful spreading erythema. [3] The wound may also progress to an infected state depending on the state of the invading microbe as well as the host. [3]

Previous report shows millions of people suffering from nonhealing or wounds complicated by infections every year despite advances in infection control. [13] These are serious problems in most developing countries including Nigeria, where preventable and curable wound infections have become contaminated with virulent and resistant strains. [10, 13-14] This is further complicated by increasing prevalence of multidrug resistant pathogens acquired from either health care setting environment, health care personnel, or inpatients and the misuse of antibiotics by the public. $[13,15-16]$ Undoubtedly, patient suffers some form of inconveniences including burden on financial resources and the increasing requirement for costeffective management within the healthcare system. [13, 17-19] It is therefore important to identify those wounds in which healing is impaired as a result of infection or heavy bacterial burden and in which systemic or topical antimicrobial treatment will be of benefit. [11]
Knowledge of the causative agents and choice of treatment are essential factors for adequate institution of appropriate antimicrobial therapy. As previously reported, antibiotic sensitivity testing should be carried out side by side as a confirmatory diagnosis to determine the infection and the causative agent. This study was conducted to characterize the bacterial isolates from wound infections at the University of Port Harcourt Teaching Hospital (UPTH) Nigeria with the view of determining their susceptibility pattern to selected antibiotics.

Table 1: Number of samples collected from the different wards in the UPTH

\begin{tabular}{cc}
\hline Ward & No. of samples collected \\
\hline Male Orthopedic ward & 11 \\
Female Orthopedic ward & 6 \\
Male Medical ward & 4 \\
Male Accident and Emergency ward & 5 \\
Female Accident and Emergency ward & 1 \\
Male Surgical ward & 3 \\
Female Surgical ward & 3 \\
Male Internal medicine ward & 2 \\
Female Internal medicine ward & 6 \\
Male General Out-Patient Department & 2 \\
(GOPD) ward & 2 \\
Female General Out-Patient Department & 5 \\
(GOPD) ward & 50 \\
Male Burns Unit & \\
\hline Total &
\end{tabular}

\section{MATERIALS AND METHODS}

Samples Collection

A total of fifty (50) infected wound samples were collected from male and female patients at different wards namely; orthopedic, surgery, medical, accident and emergency, general outpatient department (GOPD) dressing room and the burns unit of the University of Port Harcourt Teaching Hospital (Table 1). The samples were collected using sterile swab sticks rubbed firmly over the patients wound surface using parallel strokes with slow rotation of the swab and then repeating this at right angles to the first strokes as previously described. [2, 13] The samples were labeled and transferred aseptically to pharmaceutical microbiology laboratory, University of Port Harcourt for examination. [3, 20-21]

\section{Ethical approval}

This study was approved by the research and ethics committee of the University of Port Harcourt Teaching Hospital.

Inoculation technique

At the Laboratory, the swab sticks tips were cut off aseptically using a flamed and cooled pair of scissors into bijou bottles containing inoculating nutrient broth. The bijou bottles now containing samples were then incubated in Memmert incubator (Germany) at $37^{\circ} \mathrm{C}$ for up to 24 hours to allow for microbial growth.

\section{Isolation of pure culture}

The streak plate method was used in isolating pure culture of each sample. [2] The streak plate method is a simple but rapid method used in diluting the sample 
by mechanical means. A sterile loop was dipped into the bottle containing the nutrient broth and swab stick inoculated 24 hours before, and then a loopful of the broth culture was streaked across the dried agar surface of different agar media: Mannitol salt agar (Lab M, England), MacConkey agar (Lab M, England) and Cetrimide nutrient agar (Lab M, England). [13, 22] The agar plate was then incubated in Memmert incubator (Germany) for another 24 hours at $37^{\circ} \mathrm{C}$ to allow for microbial growth. Plates showing distinct colonies were selected to be used for identification and characterization. From purified plates, colonies were collected to be maintained in slants made from nutrient agar for future use. Each slant was carefully labeled and sub-cultured by streaking in successive areas of a freshly dried agar plates and incubated at $37^{\circ} \mathrm{C}$ for 24 hours. Purity of each isolate was confirmed by their colonial morphology and Gram staining. [23-25] All samples from the point of collection to identification and characterization were carefully labeled to prevent mix ups and subsequent error in result.

\section{Identification of isolates}

The isolated organisms were identified by their cultural, gram reaction, microscopic and biochemical reactions using standard methods. [23-25]

\section{Antibiotic susceptibility testing}

The susceptibility patterns of the isolated organisms were determined through tests using a wide range of antibiotics comprising of single antibiotics discs (Oxoid, UK) impregnated with known concentration of antimicrobial agent. The discs were placed on plates of solidified Mueller Hinton agar (Lab M, England) uniformly inoculated with the test organisms and allowed to diffuse for 15 minutes before incubation. [20, 26] A list of the antibiotics used for the different microorganisms include, Pseudomonas aeruginosaCeftazidime $(30 \mu \mathrm{g})$, Gentamicin $(30 \mu \mathrm{g})$, Piperacillin / Tazobactam $(110 \mu \mathrm{g})$, Cefepime $(30 \mu \mathrm{g})$, Imipenem

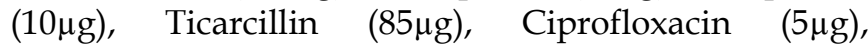
Levofloxacin $(5 \mu \mathrm{g})$, Aztreonam $(30 \mu \mathrm{g})$. Escherichia coli /

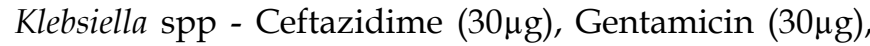
Imipenem $(10 \mu \mathrm{g})$, Ciprofloxacin $(5 \mu \mathrm{g})$, Levofloxacin

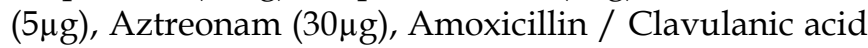
$(30 \mu \mathrm{g}), \quad$ Sulfamethoxazole-Trimethoprim $\quad(25 \mu \mathrm{g} / 1.25$

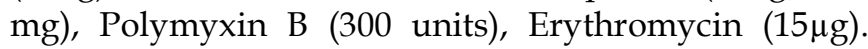
Staphylococcus aureus - Ceftazidime $(30 \mu \mathrm{g})$, Oxacillin $(1 \mu \mathrm{g}), \quad$ Vancomycin $(30 \mu \mathrm{g}), \quad$ Gentamicin $(30 \mu \mathrm{g})$, Erythromycin $(15 \mu \mathrm{g})$, Ciprofloxacin $(5 \mu \mathrm{g})$, Levofloxacin

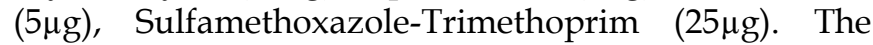
impregnated plates were incubated for 24 hours at $37^{\circ} \mathrm{C}$ and observed to see whether there was any zone of inhibition. Zone of inhibition was interpreted based on the Clinical Laboratory Science Institute (CLSI) standards. $[20,26]$

\section{RESULTS}

Number and percentage occurrence of bacterial isolates
Fifty samples were collected from patients with varying degree of wound infections between March and April 2015 from twelve (12) different wards at the University of Port Harcourt Teaching Hospital (UPTH). Out of fifty wound samples collected majority of the patients were males $32(64 \%)$ as opposed to $18(36 \%)$ for females (Table 1). The number and percentage occurrence of each individual bacterium encountered are presented in Table 2. The microbial isolate $P$. aeruginosa was seen to have the highest frequency of occurrence of $48.6 \%$ accounting for 36 of the 74 bacteria isolates. This was followed by S. aureus and E. coli accounting for $23.0 \%$ and $14.9 \%$ (or 17 and 11) of the bacterial isolates respectively. K. pneumoniae was the least prevalent bacterium accounting for $10(13.5 \%)$ of the total bacterial isolate.

Table 2: Number and percentage occurrence of each bacteria species isolated in the 50 samples.

\begin{tabular}{ccc}
\hline Organism & No of occurrence & Percentage occurrence \\
\hline Pseudomonas aeruginosa & 36 & 48.6 \\
Staphylococcus aureus & 17 & 23.0 \\
Escherichia coli & 11 & 14.9 \\
Klebsiella pneumoniae & 10 & 13.5 \\
\hline Total & $\mathbf{7 4}$ & $\mathbf{1 0 0}$ \\
\hline
\end{tabular}

Table 3: Pattern of Poly-microbial growth.

\begin{tabular}{ccc}
\hline Organisms occurring together & $\begin{array}{c}\text { No of } \\
\text { occurrence }\end{array}$ & $\begin{array}{c}\text { Percentage } \\
\text { occurrence }\end{array}$ \\
\hline P. aeruginosa/S. aureus & 8 & 42.0 \\
P. aeruginosa/ K. pneumoniae & 4 & 21.1 \\
P. aeruginosa/ E. coli & 4 & 21.1 \\
P. aeruginosa/K. pneumoniae/S. aureus & 2 & 10.5 \\
P. aeruginosa/S. aureus/E. coli & 1 & 5.30 \\
\hline Total & $\mathbf{1 9}$ & $\mathbf{1 0 0}$ \\
\hline
\end{tabular}

\section{Pattern of poly-microbial growth}

Microbial growth during this study showed both polymicrobial and mono-microbial pattern. Some samples showed a single bacterium while others were either two or more bacteria and the results are presented in Table 3.

\section{Antimicrobial susceptibility pattern of bacterial isolates}

Results of the antibiotic susceptibility testing were interpreted as resistant, intermediate or susceptible based on guidelines on antimicrobial susceptibility testing for conventional drugs by the National Committee for Clinical Laboratory Standards (NCCLS) now known as Clinical Laboratory Standards Institute (CLSI). [26] All isolates showed high frequency of resistance to cefepime and ceftazidime, and high susceptibility to imipenem; K. pneumoniae and E. coli showed high resistance to aztreonam and amoxicillinclavulanic acid. As presented in Fig. 1, P. aeruginosa showed $100 \%$ resistance to ceftazidime like all the other isolates, and $100 \%$ resistance to cefepime, aztreonam, piperacillin-tazobactam, ticarcillin but susceptible to imipenem, variable susceptibility pattern to gentamicin, and $50 \%$ susceptibility to ciprofloxacin and levofloxacin. 


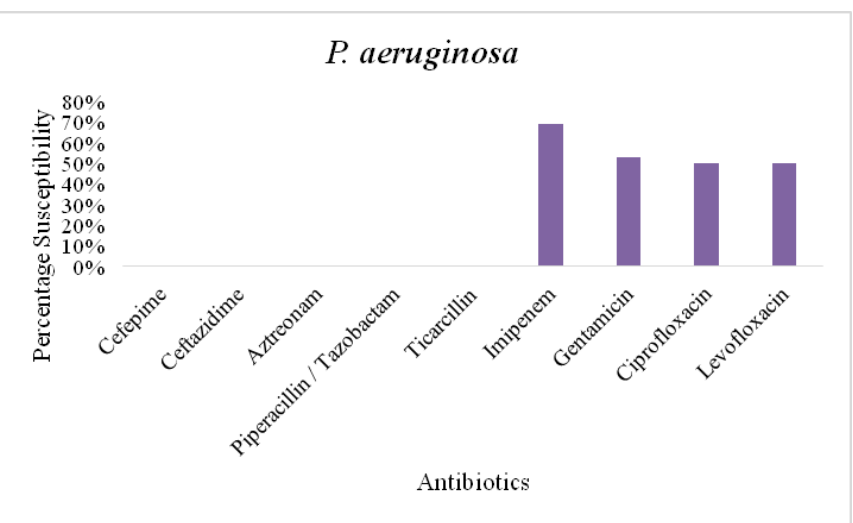

Fig. 1: Susceptibility pattern of Pseudomonas aeruginosa

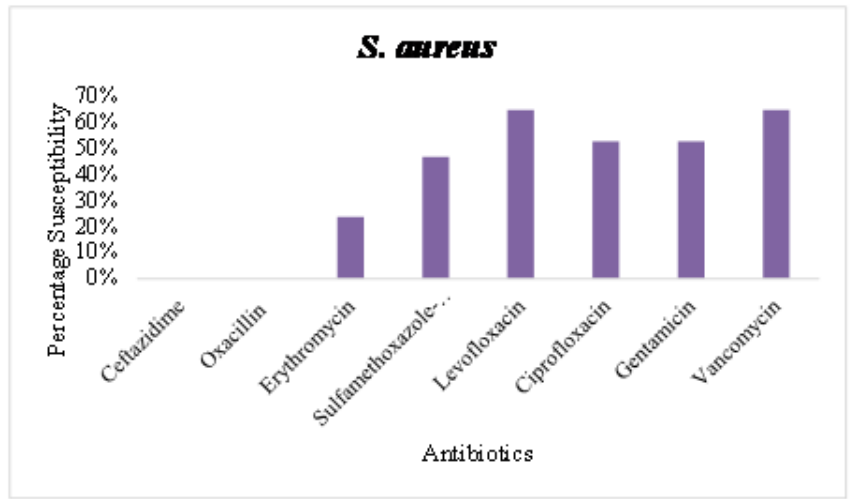

Fig. 2: Susceptibility pattern of Staphylococcus aureus

K. pneumoniae

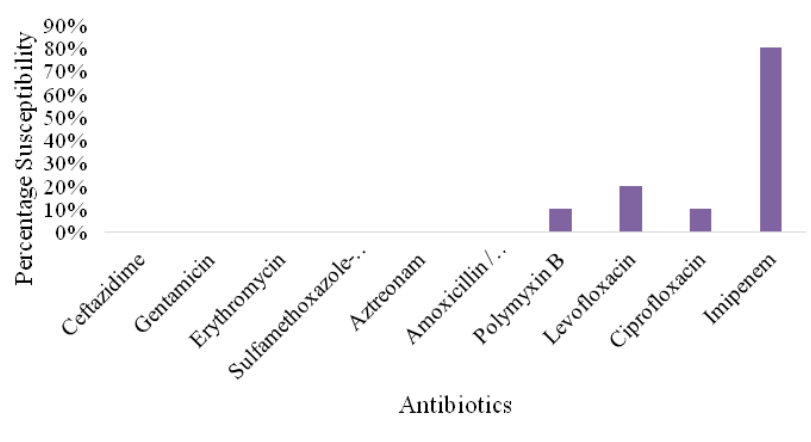

Fig. 3: Susceptibility pattern of Klebsiella pneumoniae

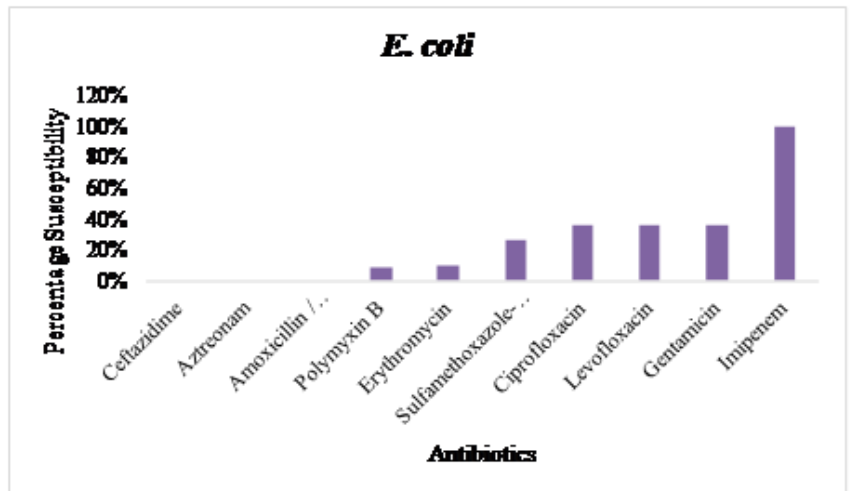

Fig. 4: Susceptibility pattern of Escherichia coli

Resistance and susceptibility pattern of Staphylococcus aureus

Staphylococcus aureus showed $100 \%$ resistance to ceftazidime, and oxacillin, $76 \%$ resistance to erythromycin, 53\% resistance to SulfamethoxazoleTrimethoprim, and a slightly above average susceptibility pattern to ciprofloxacin, gentamicin and levofloxacin of $53 \%, 53 \%$ and $65 \%$ respectively (Fig. 2).

Resistance and susceptibility pattern of Klebsiella pneumoniae

Resistance and susceptibility pattern of Klebsiella pneumoniae presented in Fig. 3 showed multiple drug resistance, with $100 \%$ resistance to ceftazidime, gentamicin, erythromycin, sulfamethoxazoletrimethoprim, aztreonam, amoxicillin-clavulanic acid, $90 \%$ resistance to polymixin B and ciprofloxacin, $80 \%$ resistance to levofloxacin and a high susceptibility $(80 \%)$ to imipenem.

Resistance and susceptibility pattern of Escherichia coli

Escherichia coli also showed multiple drug resistance, with $100 \%$ resistance to ceftazidime, aztreonam, amoxicillin-clavulanic acid, 91\% resistance to polymixin $\mathrm{B}$ and erythromycin, $73 \%$ resistance to sulfamethoxazole-trimethoprim, $64 \%$ resistance to ciprofloxacin, levofloxacin, gentamicin and 100\% susceptible to imipenem (Fig. 4).

\section{DISCUSSION}

The present study shows Pseudomonas aeruginosa with the highest frequency of occurrence of $48.6 \%$ followed by Staphylococcus aureus and Escherichia coli with a percentage occurrence of $23 \%$ and $14.9 \%$ respectively. Klebsiella pneumoniae was least occurring with $13.5 \%$ of the total bacteria isolates. Out of the seventy-four (74) isolates, fifty-seven $(77 \%)$ were Gram-negative while seventeen $(23 \%)$ were Gram-positive with P. aeruginosa being the most prevalent Gram-positive organism. The data regarding the above clinical isolates and their prevalence in wound infection is consistent with other studies reported from Nigeria and outside. ${ }^{[6,10,27-36]}$ As shown in the results of this study, majority of the patients with wound infection were males with $64 \%$ incidence rate as opposed to $36 \%$ for females. The result obtained is also consistent with previous studies within and outside Nigeria. ${ }^{[14,15,37-39]}$ It is likely due to the fact that males all over the world are much more involved in construction works, transportation, industry works, farming, fishing and lots of other physical activities that may damage an area of the body more than females. [1] In the present study, twenty-six percent $(26 \%)$ of the samples showed poly-microbial growth while fifty-four percent $(54 \%)$ showed mono-microbial growth. This result is similar, to an earlier study in India $(86-100 \%)$ and Pakistan $(98 \%)$, where high percentage of monomicrobial growth was reported. [40-42] The polymicrobial growth showed a pattern of higher prevalence of co-infections involving $P$. aeruginosa and S. aureus $(42 \%)$ followed by $P$. aeruginosa/K. pneumoniae (21.1\%), P. aeruginosa/E. coli (21.1\%), P. aeruginosa/K. pneumoniae/S. aureus (10.5\%), and finally P. aeruginosa/S. aureus/E. coli (5.3\%). The increased cases of $P$. aeruginosa and $S$. aureus occurring together among the poly-microbial infections are in line with an earlier study. [13-32] In acute soft tissue infections, polymicrobial 
aerobic-anaerobic interactions are reported to play a major role in disease progression and severity. [3] Amongst the Gram-negative bacteria, K. pneumoniae showed the highest resistance rate, being resistant to over $90 \%$ of the antibiotics used against it, but susceptible to imipenem. $P$. aeruginosa showed susceptibility to four of the test antibiotics as opposed to $E$. coli which showed multiple drug resistance pattern to all the test drugs except imipenem. S. aureus, the only Gram-positive bacteria was found to be $50 \%$ susceptible and $50 \%$ resistant to the test antibiotics.

As showed in Fig. 2, susceptibility of $S$. aureus to vancomycin $(65 \%)$ differed with previous studies in South Africa by Ferraz et al. ${ }^{[33]}$ and Amod et al. ${ }^{[44]}$ In those reports, S. aureus showed intermediate resistance to vancomycin possibly due to difference in environmental factors, drug misuse and genetic factors of the bacterium contributing to their sensitivity or resistance. The pattern of $S$. aureus resistance to erythromycin, oxacillin, trimethoprim obtained in this study was however similar to earlier an study by Fanelli et al. ${ }^{[45]}$ comparing the susceptibility patterns between the patients who are using antibiotics and those who are not using antibiotics. The overall multiple drug resistance (that is, resistance to two and above antimicrobial classes) of the bacteria isolates in this study was $>85 \%$ which was in agreement with previous study by Biadglegne et al. ${ }^{[14]}$ Mulu et al. [46] and Bayram et al. [47] The susceptibility rate of $P$. aeruginosa varied compared with the sensitivity patterns to different anti-pseudomonal drugs reported worldwide. Previous studies conducted at different parts of the world showed $P$. aeruginosa was susceptible to ceftazidime as compared to the result obtained in this study. ${ }^{[4-49]}$ In this study, $P$. aeruginosa is shown to be resistant against ceftazidime, but susceptible to gentamicin and ciprofloxacin as previously reported. [50-52] These variations in sensitivity patterns of $P$. aeruginosa may be due to the condition of the environment, genetic variations or the misuse of these antibiotics by patients. For E. coli, resistance to antimicrobials was high, with ceftazidime, aztreonam, amoxicillin-clavulanic acid at the top $(100 \%)$, followed by polymixin $\mathrm{B}$ and erythromycin, $73 \%$ resistance to sulfamethoxazole-trimethoprim, $64 \%$ resistance to ciprofloxacin, levofloxacin, gentamicin and 100\% susceptible to imipenem. The non-inhibition of E. coli may be as a result of the frequent use of these drugs by patients. Similar studies in Slovenia by Petkovsjek et al. [53] presented erythromycin as not being active against the test organism and in agreement with earlier studies carried out by Orrett and Shurland, [54] Bharathi et al. [55] Briscoe et al. [56] Kurutepe et al. [57] Iqbal et al. [58] For K. pneumoniae, the pattern of antibiotics activity presented in Fig. 3 seems to be consistent with earlier study conducted in Ethiopia by Biadglegne et al. ${ }^{[14]}$ Mulu et al. [22] Endalafer et al. [59] Although, its resistance to ciprofloxacin in this study was higher $(90 \%)$ than the reported resistance in the study done in Ethiopia $(35.7 \%)$. The response of the different microorganism and their effect on wound has been widely reported. $S$. aureus and $P$. aeruginosa are associated the most with delayed healing; this might be because of their ability to produce potentially destructive virulence factors than others. $[3,8,60]$

Previous report shows that cooperation amongst microorganisms can play a role in the net sensitivity or resistant pattern of the organisms and/or the degree of infection. ${ }^{[3,61]}$ This could occur in many ways, some of which includes the depletion of available oxygen by aerobic organisms, the production of specific nutrient by one organism encouraging the growth of fastidious and potentially pathogenic organisms cohabiting together. [3] The anaerobes provide a competitive advantage amongst themselves because of their ability to impair host cell function. ${ }^{[3]}$ Nevertheless, the efficacy of the host immune response in dealing with wound microflora is an important factor in wound healing and infection. [3] As earlier noted, microorganisms can as well contribute to the disruption of immune response thereby putting the patient at greater risk of infection. The likelihood of an infection in this instance can be addressed by looking at the host and the invading microorganism together. As the controversy regarding the sensitivity to available antimicrobial agent continues, there is a need to identify and develop new antimicrobials that are broadly effective, safe and have low propensity to induce resistance. Also, the need to control microbial populations that inhabits wound surface to reduce the chances of infection, minimize their spread as well as eliminating the chances for cross-infection. ${ }^{[3]}$ Several authors have recommended wound dressing as an important control measure that is capable of physically preventing and/or reducing the transmission of pathogenic organisms. [3, 62-63]

The most common microorganisms associated with wound infections in patients at the University of Port Harcourt Teaching Hospital in Port Harcourt, Nigeria are Pseudomonas aeruginosa, Staphylococcus aureus, Escherichia coli and Klebsiella pneumoniae. The bacteria isolates showed moderate susceptibility to gentamicin, ciprofloxacin and levofloxacin, high resistance to ceftazidime, erythromycin, sulphamethoxazole/ trimethoprim, cefepime, amoxicillin/clavulanic acid and aztreonam. Imipenem is thus observed to be an excellent antimicrobial drug in vitro. High resistance by microorganisms to test antimicrobial agents raises further concerns about the misuse of these agents. Hence, the need to reinforce the rational use of antimicrobial agents and encouraging the practice of aseptic techniques at all levels to reduce the emergence and spread of resistant pathogens.

\section{REFERENCES}

1. Ndip RN, Malange Takang AE, Echakachi CM, Malongue A, Akoachere JF, Ndip LM, Luma HN. In-vitro antimicrobial 
activity of selected honeys on clinical isolates of Helicobacter pylori. African health sciences 2007; 7(4):228-232.

2. Mama M, Abdissa A, Sewunet T. Antimicrobial susceptibility pattern of bacterial isolates from wound infection and their sensitivity to alternative topical agents at Jimma University Specialized Hospital, South-West Ethiopia. Annals of Clinical Microbiology and Antimicrobials 2014; 13(1):14.

3. Bowler PG, Duerden BI, Armstrong DG. Wound microbiology and associated approaches to wound management. Clinical microbiology reviews 2001; 14(2):244269.

4. Shittu AO, Kolawole DO, Oyedepo EAR. A study of wound infections in two health institutions in Ile-Ife, Nigeria. African journal of biomedical research 2002; 5(3):97-102.

5. Dai T, Huang YY, Sharma SK, Hashmi JT, Kurup DB, Hamblin MR. Topical antimicrobials for burn wound infections. Recent patents on anti-infective drug discovery 2010; 5(2):124-151.

6. Oguntibeju O, Nwobu R. Occurrence of Pseudomonas aeruginosa in post-operative wound infection. Pak J Med Sci 2004; 20(3):187-191.

7. Krijnen MR, Hekker T, Algra J, Wuisman PIJM, Van Royen BJ. Mycoplasma hominis deep wound infection after neuromuscular scoliosis surgery: the use of real-time polymerase chain reaction (PCR). European spine journal : official publication of the European Spine Society, the European Spinal Deformity Society, and the European Section of the Cervical Spine Research Society 2006; 15 Suppl 5(Suppl 5):599-603.

8. Heggers JP. Defining infection in chronic wounds: does it matter? Journal of wound care 1998; 7(8):389-392.

9. Pallua N, Fuchs PC, Hafemann B, Volpel U, Noah M, Lutticken R. A new technique for quantitative bacterial assessment on burn wounds by modified dermabrasion. The Journal of hospital infection 1999; 42(4):329-337.

10. Taiwo S, Okesina A, Onile B. In vitro antimicrobial susceptibility pattern of bacterial isolates from wound infections in university of Ilorin Teaching Hospital. Af J of Clinical and Experimental Microbiology 2002; 3(1):6-10.

11. Healy B, Freedman A. Infections. BMJ (Clinical research ed) 2006; 332(7545):838-841.

12. Nagoba BS, Wadher BJ, Rao AK, Kore GD, Gomashe AV, Ingle $\mathrm{AB}$. A simple and effective approach for the treatment of chronic wound infections caused by multiple antibiotic resistant Escherichia coli. Journal of Hospital Infection 2008; 69(2):177-180

13. Mohammed A, Seid ME, Gebrecherkos T, Tiruneh M, Moges F. Bacterial Isolates and Their Antimicrobial Susceptibility Patterns of Wound Infections among Inpatients and Outpatients Attending the University of Gondar Referral Hospital, Northwest Ethiopia. International Journal of Microbiology 2017; 2017:10.

14. Biadglegne F, Abera B, Alem A, Anagaw B. Bacterial isolates from wound infection and their antimicrobial susceptibility pattern in Felege Hiwot referral Hospital North West Ethiopia. Ethiopian journal of health sciences 2009; 19(3):173177.

15. Ohalete CN, Obi RK, EmeaKoroha MC. Bacteriology of different wound infection and their antimicrobial susceptibility patterns in Imo state Nigeria. World J Pharm Sci 2012; 1(3):1155-1172.

16. Amare B, Abdurrahman $\mathrm{Z}$, Moges B, Ali J, Muluken L, Alemayehu M, Yifru S, Sendek B, Belyhun Y, Moges F. Postoperative surgical site bacterial infections and drug susceptibility patterns at Gondar University Teaching Hospital, Northwest Ethiopia. J Bacteriol Parasitol 2011; 2(8):126.

17. Bereket $\mathrm{W}$, Hemalatha $\mathrm{K}$, Getenet $\mathrm{B}$, Wondwossen $\mathrm{T}$, Solomon A, Zeynudin A, Kannan S. Update on bacterial nosocomial infections. Eur Rev Med Pharmacol Sci 2012; 16(8):1039-1044

18. Obritsch MD, Fish DN, MacLaren R, Jung R. National surveillance of antimicrobial resistance in Pseudomonas aeruginosa isolates obtained from intensive care unit patients from 1993 to 2002. Antimicrobial agents and chemotherapy 2004; 48(12):4606-4610.

19. Anguzu J, Olila D. Drug sensitivity patterns of bacterial isolates from septic post-operative wounds in a regional referral hospital in Uganda. African health sciences 2007; 7(3):148-154.

20. Ezenobi NO, Ogbu HI, Onosigho I. Antimicrobial susceptibility pattern of urinary isolates from outpatients suspected for urinary tract infection. GSC Biological and Pharmaceutical Sciences 2018; 5(3):1-11.

21. Brook I. Collection and transportation of specimens in anaerobic infections. The Journal of family practice 1982; 15(4):775-779.

22. Mulu W, Kibru G, Beyene G, Damtie M. Postoperative Nosocomial Infections and Antimicrobial Resistance Pattern of Bacteria Isolates among Patients Admitted at Felege Hiwot Referral Hospital, Bahirdar, Ethiopia. Ethiopian journal of health sciences 2012; 22(1):7-18.

23. Cheesbrough M. Biochemical tests to identify bacteria. Laboratory Practice in Tropical Countries, Cheesbrough M (eds) Cambridge edn 2002; 63-70.

24. Sandle T. Microbiological culture media. In: Pharmaceutical Microbiology. Oxford: Woodhead Publishing 2016; 47-61.

25. Ezenobi NO, Ogbu HI, Eneogwe NC. Microbiological assessment of biofilm formation on different water storage containers. GSC Biological and Pharmaceutical Sciences 2018; 5(3):115-123.

26. Stamdards A. Performance standards for antimicrobial susceptibility testing. Approved Standards CLSI 2010;M100S120.

27. Gebre-Sealsssie S. Antimicrobial resistance patterns of clinical bacterial isolates in southwestern Ethiopia. Ethiopian medical journal 2007; 45(4):363-370.

28. Khan NA, Saba N, Abdus A, Ali A. Incidence and antibiogram patterns of Escherichia coli isolated from various clinical samples from patients at NIH Islamabad. Pak J Biol Sci 2002; 5(1):111-113

29. Sanderson PJ, Wren MW, Baldwin AW. Anaerobic organisms in postoperative wounds. J Clin Pathol 1979; 32(2):143-147.

30. Brook I. A 12 year study of aerobic and anaerobic bacteria in intra-abdominal and postsurgical abdominal wound infections. Surgery, gynecology \& obstetrics 1989; 169(5):387392.

31. Wheat LJ, Allen SD, Henry M, Kernek CB, Siders JA, Kuebler $\mathrm{T}$, Fineberg N, Norton J. Diabetic foot infections. Bacteriologic analysis. Archives of internal medicine 1986; 146(10):1935-1940.

32. Mousa HA. Aerobic, anaerobic and fungal burn wound infections. The Journal of hospital infection 1997; 37(4):317323.

33. Bariar LM, Vasenwala SM, Malik A, Ansari GH, Chowdhury TE. A clinicopathological study of infections in burn patients and importance of biopsy. Journal of the Indian Medical Association 1997; 95(11):573-575.

34. Lawrence JC. The bacteriology of burns. The Journal of hospital infection 1985; 6 Suppl B:3-17.

35. Revathi G, Puri J, Jain BK. Bacteriology of burns. Burns: journal of the International Society for Burn Injuries 1998; 24(4):347-349.

36. Vindenes $H$, Bjerknes $R$. Microbial colonization of large wounds. Burns: journal of the International Society for Burn Injuries 1995; 21(8):575-579.

37. Taye M. Wound infection in Tikur Anbessa hospital, surgical department. Ethiopian medical journal 2005; 43(3):167-174.

38. Goswami NN, Trivedi HR, Goswami APP, Patel TK, Tripathi CB. Antibiotic sensitivity profile of bacterial pathogens in postoperative wound infections at a tertiary care hospital in Gujarat, India. Journal of pharmacology \& pharmacotherapeutics 2011; 2(3):158-164.

39. Amoran O, Sogebi A, Fatugase O. Rates and Risk Factors Associated with Surgical Site Infections in a Tertiary Care 
Center in South-Western Nigeria. Int J Trop Dis Health 2013; 3(1):25-36.

40. Suchitra JB, Lakshmidevi N. Surgical site infections: Assessing risk factors, outcomes and antimicrobial sensitivity patterns. Afr J Microbiol Res 2009; 3(4):175-179.

41. Sanjay KR, Prasad MNN, Vijaykumar GS. A study on isolation and detection of drug resistance gram negative bacilli with special importance to post operative wound infection. Journal of Microbiology and Antimicrobials 2010; 2(6):68-75.

42. Basu S, Panray TR, Gulati AK, Singh TB, Shukla VK. A Prospective, Descriptive Study to Identify the Microbiological Profile of Chronic Wounds in Outpatients. Wound Management \& Prevention 2009; 55(1):14-20.

43. Ferraz V, Duse AG, Kassel M, Black AD, Ito T, Hiramatsu K. Vancomycin-resistant Staphylococcus aureus occurs in South Africa. South African medical journal 2000; 90(11):1113.

44. Amod F, Moodley I, Peer AK, Sunderland J, Lovering A, Wootton M, Nadvi S, Vawda F. Ventriculitis due to a hetero strain of vancomycin intermediate Staphylococcus aureus (hVISA): successful treatment with linezolid in combination with intraventricular vancomycin. The Journal of infection 2005; 50(3):252-257.

45. Fanelli M, Kupperman E, Lautenbach E, Edelstein PH, Margolis DJ. Antibiotics, acne, and Staphylococcus aureus colonization. Archives of dermatology 2011; 147(8):917-921.

46. Mulu A, Moges F, Tessema B, Kassu A. Pattern and multiple drug resistance of bacterial pathogens isolated from wound infection at University of Gondar Teaching Hospital, Northwest Ethiopia. Etiop Med J 2006; 44(2):125-131.

47. Bayram Y, Parlak M, Aypak C, Bayram I. Three-year review of bacteriological profile and antibiogram of burn wound isolates in Van, Turkey. International journal of medical sciences 2012; 10(1):19-23.

48. Wi YM, Choi JY, Lee JY, Kang CI, Chung DR, Peck KR, Song $\mathrm{JH}$, Ko KS. Antimicrobial Effects of beta-Lactams on Imipenem-Resistant Ceftazidime-Susceptible Pseudomonas aeruginosa. Antimicrobial agents and chemotherapy 2017; 61(6).

49. Aubert D, Poirel L, Chevalier J, Leotard S, Pages J-M, Nordmann P. Oxacillinase-Mediated Resistance to Cefepime and Susceptibility to Ceftazidime in Pseudomonas aeruginosa. Antimicrobial agents and chemotherapy 2001; 45(6):1615-20.

50. Karlowsky JA, Draghi DC, Jones ME, Thornsberry C, Friedland IR, Sahm DF. Surveillance for antimicrobial susceptibility among clinical isolates of Pseudomonas aeruginosa and Acinetobacter baumannii from hospitalized patients in the United States, 1998 to 2001. Antimicrobial agents and chemotherapy 2003; 47(5):1681-1688.
51. Bertrand X, Thouverez M, Patry C, Balvay P, Talon D. Pseudomonas aeruginosa: antibiotic susceptibility and genotypic characterization of strains isolated in the intensive care unit. Clinical Microbiology and Infection 2001; 7(12):706708.

52. Orrett FA. Antimicrobial susceptibility survey of Pseudomonas aeruginosa strains isolated from clinical sources. Journal of the National Medical Association 2004; 96(8):1065-1069.

53. Petkovsek Z, Elersic K, Gubina M, Zgur-Bertok D, Starcic Erjavec M. Virulence potential of Escherichia coli isolates from skin and soft tissue infections. Journal of clinical microbiology 2009; 47(6):1811-1817.

54. Orrett FA, Shurland SM. Prevalence of Resistance to Antimicrobials of Escherichia coli Isolates from Clinical Sources at a Private Hospital in Trinidad. Jpn J Infect Dis 2001; 54(2):64-68.

55. Bharathi M, Ramakrishnan R, Maneksha V, Shivakumar C, Nithya V, Mittal S. Comparative bacteriology of acute and chronic dacryocystitis. Eye 2007;1-8.

56. Briscoe D, Rubowitz A, Assia EI. Changing bacterial isolates and antibiotic sensitivities of purulent dacryocystitis. Orbit (Amsterdam, Netherlands) 2005; 24(2):95-98.

57. Kurutepe S, Surucuoglu S, Sezgin C, Gazi H, Gulay M, Ozbakkaloglu B. Increasing antimicrobial resistance in Escherichia coli isolates from community-acquired urinary tract infections during 1998-2003 in Manisa, Turkey. Japanese journal of infectious diseases 2005; 58(3):159-161.

58. Iqbal M, Pate I, Ain Q, Barney N, Kiani Q, Rabbani K, Zaidi G, Mehdi B. Susceptibility Patterns of Escherichia coli: Prevalence of Multidrug-resistant Isolates and Extended Spectrum Beta Lactamase Phenotype. J Pak Med Asso 2002; 52:407-417.

59. Endalafer N, Gebre-Selassie S, Kotiso B. Nosocomial bacterial infections in a tertiary hospital in Ethiopia. Journal of Infection Prevention 2011; 12(1):38-43.

60. Danielsen L, Balslev E, Doring G, Hoiby N, Madsen SM, Agren M, Thomsen HK, Fos HH, Westh H. Ulcer bed infection. Report of a case of enlarging venous leg ulcer colonized by Pseudomonas aeruginosa. APMIS : acta pathologica, microbiologica, et immunologica Scandinavica 1998; 106(7):721-726.

61. Wingreen NS, Levin SA. Cooperation among Microorganisms. PLOS Biology 2006; 4(9):e299.

62. Mertz PM, Marshall DA, Eaglstein WH. Occlusive wound dressings to prevent bacterial invasion and wound infection. Journal of the American Academy of Dermatology 1985; 12(4):662-668.

63. Jennings R, Reeder S, Smith TL, Potter CW. Surgical wound dressings as barriers to an enveloped virus. The Journal of hospital infection 1990; 16(2):133-140.

HOW TO CITE THIS ARTICLE: Ezenobi NO, Ogbu HI, Musa GO. In vitro Antimicrobial Susceptibility Testing of Bacterial Isolates Causing Wound Infection in a Tertiary Care Hospital, Port Harcourt, Nigeria. Int. J. Pharm. Sci. Drug Res. 2019; 11(5): 157-163. DOI: 10.25004/IJPSDR.2019.110502 